\title{
Molecular cytogenetic analysis of formalin-fixed, paraffin-embedded solid tumors by comparative genomic hybridization after universal DNA- amplification
}

\author{
Michael R.Spelcher*, Stanislas du Manoir, Evelln Schröck, Heldi Holtgreve-Grez, Brigitte Schoell, \\ Christoph Lengauer ${ }^{+}$, Thomas Cremer and Thomas Ried \\ Institut für Humangenetik, Unverstăt Headelberg, Im Neuenheamer Fedd 328, D-69120 Heidedberg, Germany
}

Received June 25, 1993; Revised and Accepted August 29, 1993

\begin{abstract}
We present a technique which allows the detection and chromosomal localization of DNA sequence copy number changes in solld tumor genomes from frozen sections and paraffin embedded, formalln fixed specimens. Based on comparative genomic hybridization and on universal DNA amplification procedures this technique is possible even if only a few tumor cells are avallable. We demonstrate the feasibllity of this method to visualize complete and partial chromosome gains and losses and gene amplifications in archived solld tumor samples.
\end{abstract}

\section{INTRODUCTION}

Data about neoplasia-associated chromosome aberrations are increasing at a rapid rate. The vast majority, however, relates only to hematologic disorders while informations about solid tumors are still scarce (1). Banding analyses of chromosomal changes in solid tumors have often been hampered by low mitotic indices and poor quality metaphase preparations. They usually depend on cell cultures which are problematic, because secondary changes or selective growth advantages may veil the visualization of crucial aberrations. Moreover, the nature of many rearranged chromosomes as well as the origin of sequences amplified in homogeneously staining regions (HSRs) or double minute chromosomes (DMs) cannot be established by karyotypic analysis.

A procedure for the global screening of copy number sequence changes within a tumor genome solely from archival tissue material could increase our knowledge about cytogenetic alterations in solid tumors significantly. With the vast amounts of archival specimens available, a direct comparison of these cytogenetic data with histological and histochemical results and clinical follow up data would become possible. Here we present such a technique which can be applied on paraffin embedded, formalin fixed solid tumors even if only a small number of tumor cells are available. It is based on the recently introduced technique of comparative genomic hybridization (CGH) $(2,3)$ and protocols for universal DNA amplification $(4,5)$.

CGH represents a new approach to screen a tumor genome for genetic imbalances $(2,3)$. DNA isolated from the tumor and normal reference DNA are differentially labeled and together hybridized to normal metaphase chromosomes under suppression conditions with an excess of unlabeled human Cotl DNA fraction. Detection is done with different fluorochromes, e.g. fluorescein isothiocyanate (FITC) for the tumor DNA and tetramethylrhodamine isothiocyanate (TRITC) for the normal reference DNA. The ratios of fluorescence intensities between FITC and TRITC display the over- or underrepresentation of chromosome segments in the tumor genome and thus reflect the actual copy number of DNA sequences in the tumor genome. The technique has already been used to detect monosomies and polysomies of entire chromosomes or chromosomal subregions, as well as to map gene amplifications with respect to chromosome bands $(2,3,6$, own unpublished data).

Using modified protocols for DNA extraction from paraffin embedded tissue sections and the degenerate oligonucleotide primed PCR (DOP-PCR) $(4,5)$ we detected chromosome gains and losses and identified new amplification sites in solid tumors. Some of these changes were not detected with previously performed standard cytogenetic or molecular genetic examinations.

\section{RESULTS}

The minimal amount of target DNA for DOP-PCR and subsequent CGH experiments

In order to determine the relationships between template DNA concentrations and DOP-PCR yield suitable for CGH experiments we amplified varying amounts of total genomic DNA from

\footnotetext{
* To whom correspondence should be addressed

+ Present address: Research Institute of Molecular Pathology, Dr Bohr-Gasse 7, A-1030 Wien, Austria
} 


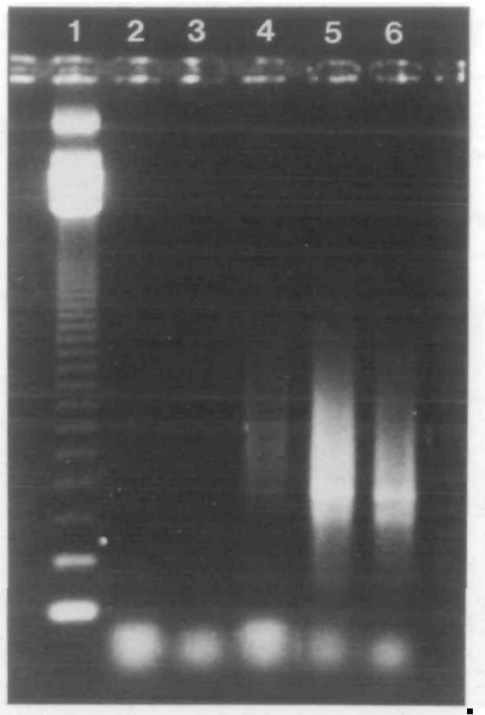

Fbgure 1. DOP-PCR products revealed a typical smear ranging from 100 bp to about $2.5 \mathrm{~kb}$. A distinct band appears at $400 \mathrm{bp}$, probably representing the amplification of repetitive DNA sequence motifs. Lane 1: $123 \mathrm{bp}$ ladder, Lane 2: $10 \mathrm{pg}$ template, 3: $50 \mathrm{pg}, 4: 100 \mathrm{pg}, 5: 25 \mathrm{ng}, 6: 100 \mathrm{ng}$.

healthy female and male donors. A reproducible amplification was achieved using as little as $100 \mathrm{pg}$ DNA with the standard DOP-PCR protocol (4) (Fig.1). Fifty pg DNA were reproducibly amplifiable, when the PCR products were ethanol precipitated and subjected to additional rounds of amplification. Smaller amounts of genomic DNA could not be amplified reproducibly.

CGH experiments were performed using these DOP-PCR products together with normal male or female reference DNA. The painting patterns of the DOP-PCR products revealed a uniform staining of all autosomes except for heterochromatic regions which are only weakly stained under suppression conditions. Accordingly, the fluorescence ratios between the fluorescence intensities of the DOP-PCR amplification products and the normal reference DNA were within the normal range. Only the sex chromosomes demonstrated different painting patterns and elevated or decreased ratio values, reflecting different sexes of the donors for the template DNA for the DOP-PCR and the reference DNA (Fig. 2). We show that DNA amounts of 100 pg and more can be reproducibly used for DOP-PCR and subsequent $\mathrm{CGH}$ experiments.

In a next step it was tested whether multiple numerical changes of DNA copy numbers in a tumor genome after DOP-PCR of small DNA amounts are still visible in CGH experiments. As a model the cell line ACHN established from a renal cell carcinoma (7) was used. This cell line was characterized by previous G-banding analysis revealing the karyotype: $53, X,-Y$, $+\operatorname{der}(1) \mathrm{t}(1 ; 10)($ pl3.1; q11.2), +2, +7, +7, +12, +12, +16, +17 (7). CGH analyses with DNA from this cell line had confirmed all numerical alterations (3). CGH with the DOP-PCR amplification product of $100 \mathrm{pg}$ of this cell line DNA showed that all numerical changes were maintained (Fig. 3A,B). A comparison of the fluorescence ratio values for $\mathrm{CGH}$ using nonamplified DNA with the DNA after DOP-PCR revealed identical results (Fig. 4).

\section{Analysis of paraffin embedded, formalin fixed tissues}

The DNA of frozen tissue sections is still present as high molecular weight DNA and can be subjected to DOP-PCR with direct, standard cell lysis protocols (as described e.g. in 8). In contrast, due to interactions of formalin between DNA and proteins the formalin fixation is the major limiting factor for the DNA analysis of archival material (9). Therefore we were particularly interested to explore the suitability of DNA extracted from paraffin embedded, formalin fixed tissues for $\mathrm{CGH}$ experiments, because these materials represent the vast majority of archival material. Usually the fixation was done with unbuffered formalin and the exact fixation times are not known. Paraffin embedded materials were stored up to several years before DNA was extracted for CGH. Several reports indicate that DNA purified from tissue fixed with unbuffered formalin for several days shows severe degradation $(9-12)$. Once embedded, however, the DNA integrity of formalin fixed tissues is well preserved even during prolonged tissue storage (9).

Several procedures for DNA preparation from paraffin embedded tissue sections were evaluated. DNA extracted with standard cell lysis protocols (8) did not allow an effective DOPPCR amplification. Use of an ion exchanger (13) could not improve the results. Testing previously published DNA extraction protocols from paraffin-embedded tissues (e.g. 10-13) an additional incubation step with sodium thiocyanate after the dewaxing improved the DNA yield and efficiency of subsequent DOP-PCR significantly (see Material and Methods). This protocol was used for all experiments.

To assess the influence of fixation with unbuffered formalin on DNA a time course of fixation ranging from 0 to 48 hours was performed using tissue obtained from a glioma. It confirmed an increase of the DNA degradation and a decrease of the yield of extractable DNA with the fixation time (data not shown). Accordingly, the efficiency of DOP-PCR diminished (Fig. 5). It therefore seemed to be unlikely that similar small amounts of DNA could be reproducibly used for universal PCR and CGH as with DNA obtained directly from a cell line or from frozen tissue sections. The smallest number of formalin fixed nuclei required for successful DOP-PCR amplification was established. We chose cells from paraffin embedded sections which were fixed with unbuffered formalin for at least 48 hours. These cells were isolated (14), counted and DNA from different cell numbers amplified. Our results indicate that generally the DNA content of some 2000 nuclei is sufficient for amplification.

In order to test the feasibility of this approach for the diagnosis of copy number sequence changes in different tissues, several normal, formalin fixed, paraffin embedded tissue sections were evaluated. This included normal tissue from kidney, testis, and skin. All experiments yielded the expected homogeneous painting pattern of all autosomes (data not shown).

To test the power of this technique for detection of numerical aberrations in archival solid tumors, a glioma, classified as anaplastic astrocytoma (grade IV), partly glioblastoma multiforme according to the WHO classification (15) was evaluated. This tumor was fixed with unbuffered formalin and paraffin embedded several years ago. It had been previously characterized by banding analyses which revealed the existence of at least two clones: 46 , XX [3 metaphases]; 47, XX, +7, +dmin [2 metaphases], and 3 metaphases with additional nonclonal losses (16). Molecular biology investigations indicated a 20-60 fold amplification of the EGFR gene at 7p13 (17). DNA was extracted from the archival tissue, $8 \mathrm{ng}$ amplified with DOP-PCR, and CGH with the amplification product performed. To rule out artifacts due to the formalin interactions or the DOP-PCR, CGH was repeated 


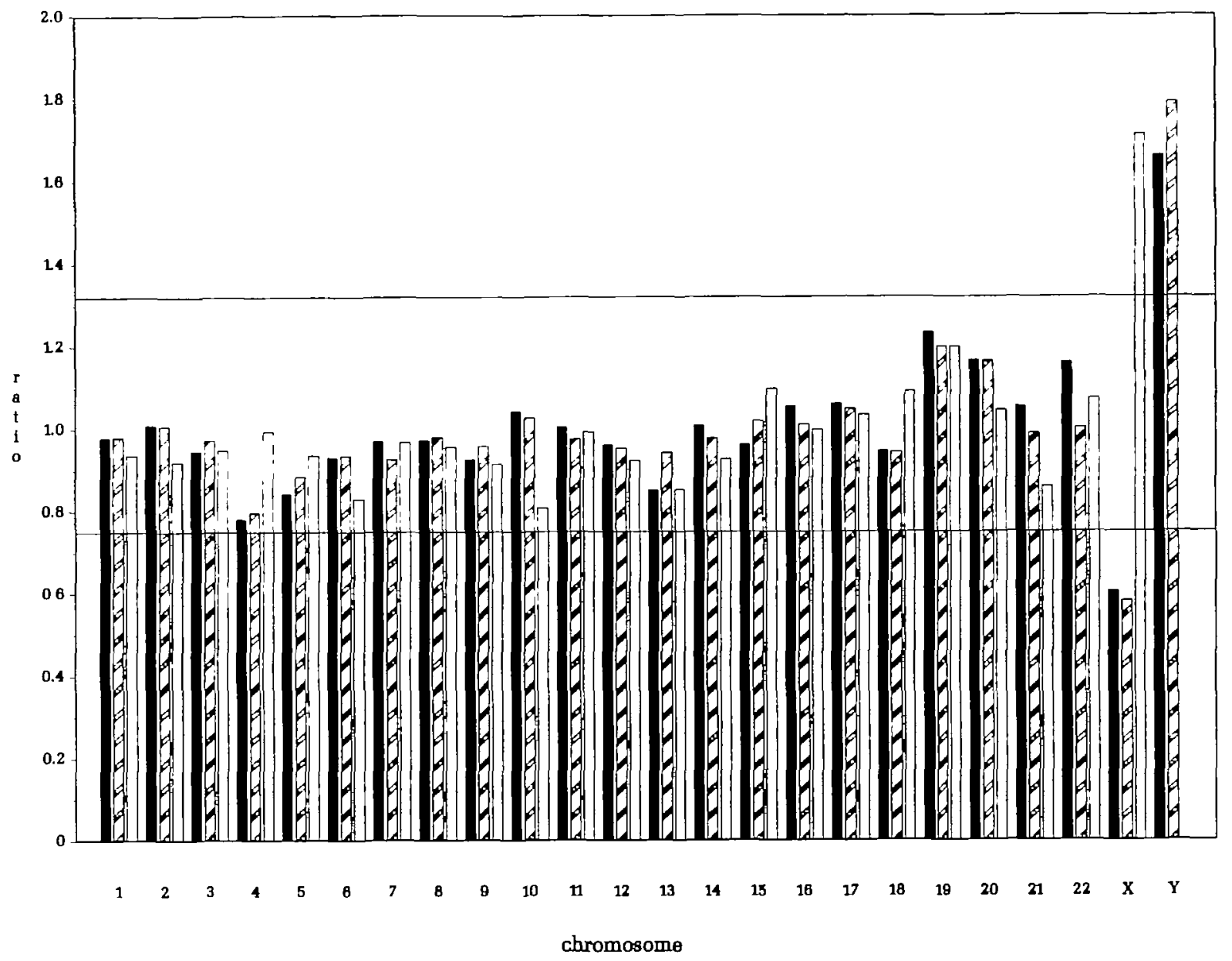

Figure 2. Flworescence ratio measurements of control CGH experiments. All ratios (FITC/TRITC) for the autosomes are within the normal range. Values outside the normal range exist only for the sex chromosomes. Solid columns: CGH with DOP-PCR amplification product from 100 pg of normal male DNA (FITC) hybridized together with normal female DNA (TRITC) on a male metaphase spread. The ratio (FITC/TRTC) for the X chromosomes is decreased reflecting the monosomy $\mathrm{X}$ in the male reference DNA (1X:2X) while the ratio for the $\mathrm{Y}$ chromosome is increased (1Y:0Y). Hatched columns: CGH with DOP-PCR amplification product from $10 \mathrm{ng}$ of normal male DNA (FITC) hybridized together with normal female DNA (TRITC) on a male metaphase spread. The ratios (FITC/TRITC) for the $\mathrm{X}$ and $\mathrm{Y}$ chromosomes are again decreased and increased, respectively. Empty columns: CGH with DOP-PCR amplification product from $100 \mathrm{ng}$ of normal female DNA (detected with FITC), hybridized together with normal male DNA (detected with TRITC) on a female metaphase spread. The ratio value (FITCTRTTC) for the X-chromosomes is now elevated.

with DNA which was directly extracted from frozen tissue of this glioma. For both experiments Fig. 6A and B show typical examples of normal metaphase spreads displaying pixel by pixel ratio images. To increase the accuracy of the comparison of the two CGH experiments FITC (tumor DNA) to TRITC (reference DNA) combined ratio profiles for 8 and 12 metaphases, respectively, were measured for all chromosomes (Fig. 7A,B). Although the variability of the ratio values obtained after $\mathrm{CGH}$ with the DOP-PCR amplification product was higher, in both experiments the gain of chromosome 7 and the amplification at $7 \mathrm{p} 13$ could be confirmed. Unexpectedly, two other amplification sites at $7 q 12$ and $1 \mathrm{q} 32$, an underrepresentation of chromosome 10 and an overrepresentation of chromosome 19 were also consistently seen in both CGH experiments Neither the two newly identified amplification sites nor the numerical aberrations of the chromosomes 10 and 19 had been diagnosed by previously performed routine cytogenetic or molecular genetic studies.

\section{DISCUSSION}

We describe a procedure which allows for the first time the establishment of a chromosomal copy number karyotype from archival formalin fixed, paraffin embedded, solid tumors even if only low numbers of tumor cells are available. This procedure combines two recently introduced techniques: CGH $(2,3)$ and a procedure for the universal amplification of DNA, the DOPPCR $(4,5)$.

CGH offers a new method to screen for genetic imbalances and for the detection and chromosomal localization of DNA sequence copy number changes anywhere in the tumor genome in a single in situ hybridization $(2,3)$. Cytogenetic analyses of copy number differences are now possible with tumor DNA alone. From several recently published protocols for 'universal' DNA amplification $(4,5,18,19)$ we chose the DOP-PCR $(4,5)$.

While some chromosomes with higher or lower fluorescence intensities after CGH experiments are often directly visible in 

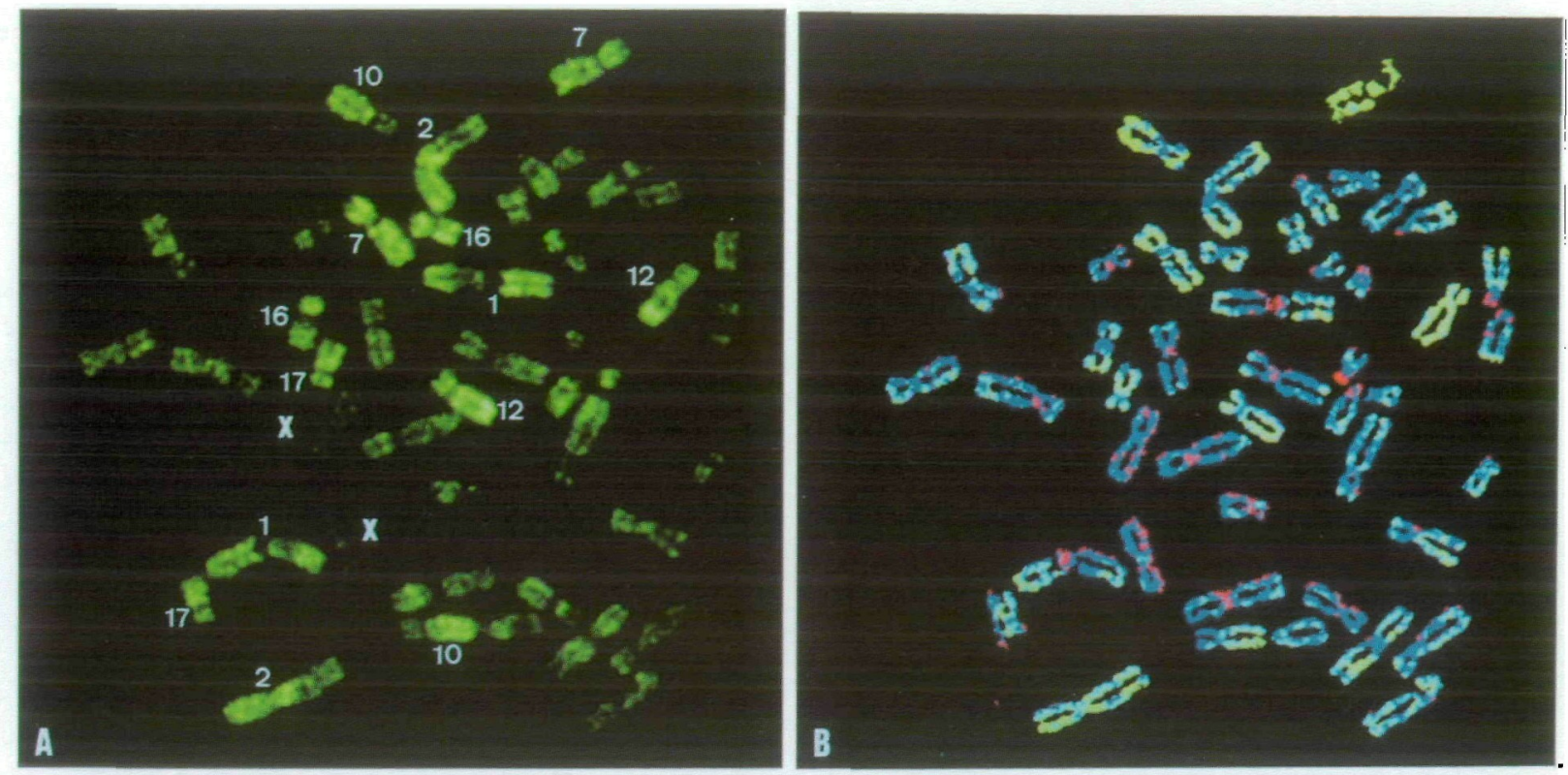

Figure 3. CGH experiment with $100 \mathrm{pg}$ of DOP-PCR amplified genomic DNA (detected with FITC) from the ACHN renal cell carcinoma cell line and reference DNA (detected with TRITC) on a normal metaphase spread. A) In the FITC image all numerical aberrations are readily visible. B) FITC to TRITC pixel by pixel fluorescence intensity ratio image of the same metaphase. Yellow: overrepresented DNA segments in the tumor genome; Blue: balanced state of chromosomal material; Red: under-representation.
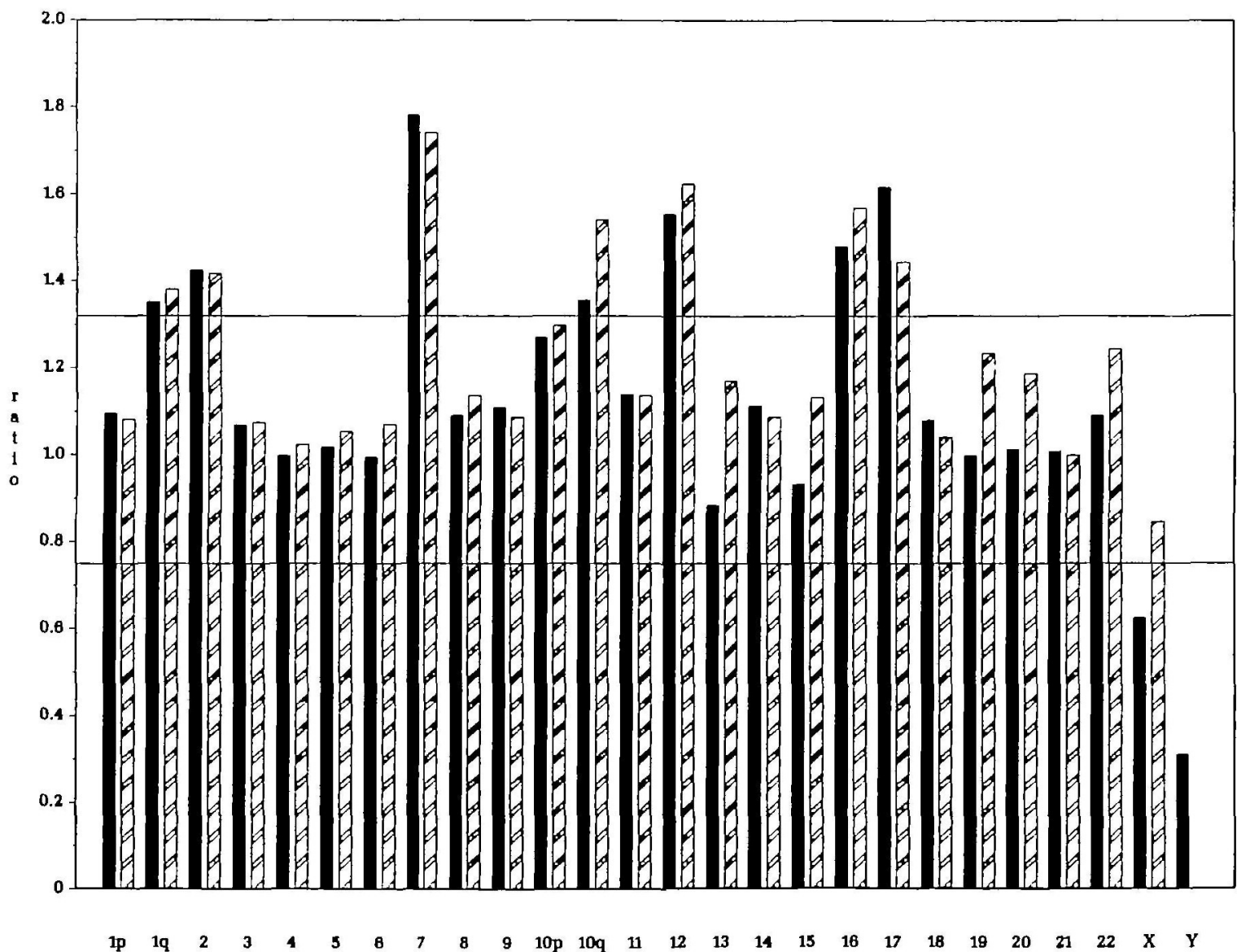
34 $910 \mathrm{p}$

chromosome

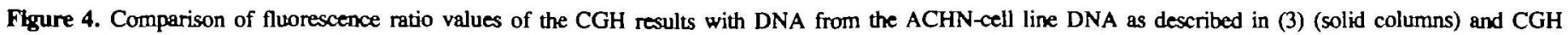
results with the DOP-PCR amplification product of $100 \mathrm{pg}$ of ACHN cell line DNA (hatched columns). 


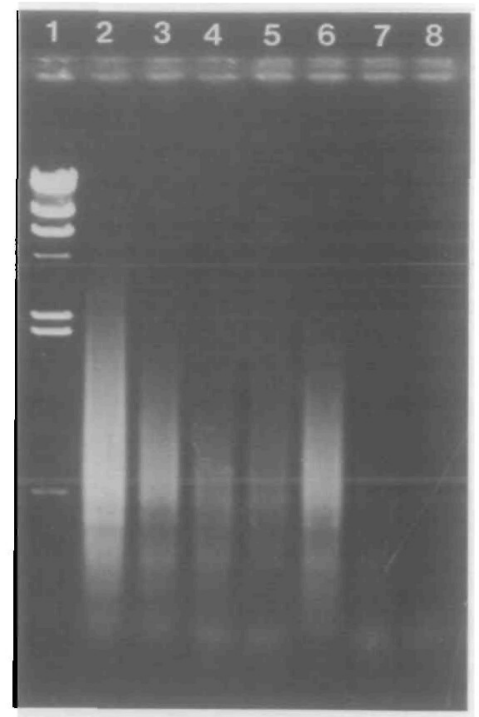

Figure 5. Influence of formalin fixation time on the DNA yield after DOP-PCR. Lane 1: Hind III marker. Lanes 2-8 show the DOP-PCR amplification products using DNA extracted from a glioma after different fixation times $(0,1,2,4$, $8,24,48 \mathrm{hrs}$ ).

the fluorescence microscope, an accurate evaluation depends on image acquisition using a cooled CCD camera and digital image analysis. The software used was developed in our laboratory particularly for the evaluation of CGH experiments (3; du Manoir et al., Manuscript in preparation). These programs allow the rapid measurement of fluorescence intensity ratios along chromosomes. The quantitative evaluations will eventually make possible automated procedures for the assessments of gains and losses, which will then be usable on a routine basis in many laboratories.

Due to the suppression conditions only a residual weak painting of chromosomal regions containing repetitive DNA sequences, e.g. centromeric regions, is achieved. This residual painting can be more intensive either for FITC or for TRITC within one experiment. However, very small differences in these 'weak painting areas' cause tremendous deviations of the ratio. Consider for example fluorescence intensity values of 138 for FITC and 128 for TRITC on a chromosome arm out of a gray scale ranging from 0 to 255. This would result in a FITC/TRITC ratio of 1.08 . In contrast, at centromeric regions weak values such as 10 for FITC and 1 for TRITC would result in a FITC/TRITC ratio value of 10 . Depending on which fluoresence is slightly more intensive, the ratio deviation can be in either way: in Figure 7A, FITC is somewhat more intensive, while in Figure 7B, TRITC has higher intensity values at the centromeric regions. The establishment of a copy number karyotype for these regions is impossible.

Since DNA remains as high molecular weight DNA if fresh tissue is frozen immediately after surgical removal $(9$, own unpublished data) the DNA of cells from such specimens is directly accessible for amplification with DOP-PCR and subsequent CGH experiments after destroying the cell membranes with standard lysis protocols, e.g. as described in (8). In contrast fixed and embedded materials represent a very heterogeneous group with several factors contributing to this heterogeneity: (a) variable lenghts of time between surgical removal of the tissue and fixation; (b) variable levels of nucleases in different tumors; (c) variable fixation times with unbuffered formalin (9).
Previously published protocols for DNA extraction from paraffin embedded tissue sections $(9-13)$ were tested and refinements evaluated. For tissues fixed with unbuffered formalin our experiments confirmed a significant degree of DNA degradation over a time course of 48 hours. This degradation, however, was not observed in tissues which were fixed with buffered formalin (4\% PBS) (own unpublished data). As described by others, the use of ionic detergents and long periods of digestion using high concentrations of a protease were found to be critical for success. An additional incubation step with sodium thiocyanate, a strong protein-denaturating agent, which dissociates DNA-nucleohistone complexes improved the DNA yield when applied after dewaxing (see Methodology). Sodium thiocyanate had previously been proven to increase the hybridization efficiency of FISH on paraffin embedded tissue sections (21).

The varying amounts of DNA from different tumors necessary for DOP-PCR reflects the differences in DNA preservation. With DNA directly obtained from a cell line, $50 \mathrm{pg}$ are sufficient for CGH experiments after DOP-PCR. Since the diploid DNA content of a cell is $6.6 \mathrm{pg}$ (20), our model experiments suggest that the DNA content of about 10 unfixed cells is sufficient. However, taking into account the DNA loss during an extraction procedure, it is likely to assume that one might need the DNA content of a higher cell number than 10 for reproducible DOPPCR with subsequent CGH. In contrast DNA from 2000 cells was necessary for DOP-PCR in case of paraffin embedded tumors fixed with unbuffered formalin. Assuming that a tumor of $1 \mathrm{~cm}^{3}$ may contain $10^{9}$ tumor cells (22), 2000 cells would represent a tumor size of about $1 \mathrm{~mm}^{3}$. Such a number of tumor cells can easily be scratched from virtually all tissue sections.

In our study tissue samples were taken which microscopically consisted solely of malignant cells. An accurate estimation of the percentage of normal cells derived from connective tissues, lymphocytes or blood vessels was not possible. We assume that the percentage of tumor cells was at least $90 \%$. Preliminary experiments to test the maximal tolerable 'contamination' with normal cells revealed that numerical changes such as monosomies or trisomies are still detectable with a 50\% portion of normal cells (own unpublished data).

Although it seems unlikely that all archival tumor materials will become analyzable by this technique due to deficiencies in fixation and embedding protocols, we have already used this technique to analyze successfully a variety of paraffin embedded tissues from brain, breast, skin, testis and lung tumors (own unpublished data). These tissues were contributed from different laboratories, fixed with unbuffered formalin for an unspecified time and stored from several months up to several years at room temperature after paraffin embedding.

In many cases sufficient DNA can be extracted from a tissue section to perform a CGH experiment even without DOP-PCR amplification. However, the combination of DOP-PCR and CGH will allow the analysis of genomic imbalances in tumors with only few cells as starting material and thus make possible a comparison of genetic changes with histological and immunohistochemical features and evaluations of the multiclonality of a tumor. Moreover, this procedure should prove most valuable for the development of diagnostic tests, since minute bioptic samples, such as fine needle aspirations, can be investigated.

While balanced translocations will not be visible with this technique, the easy chromosomal mapping of amplification sites 


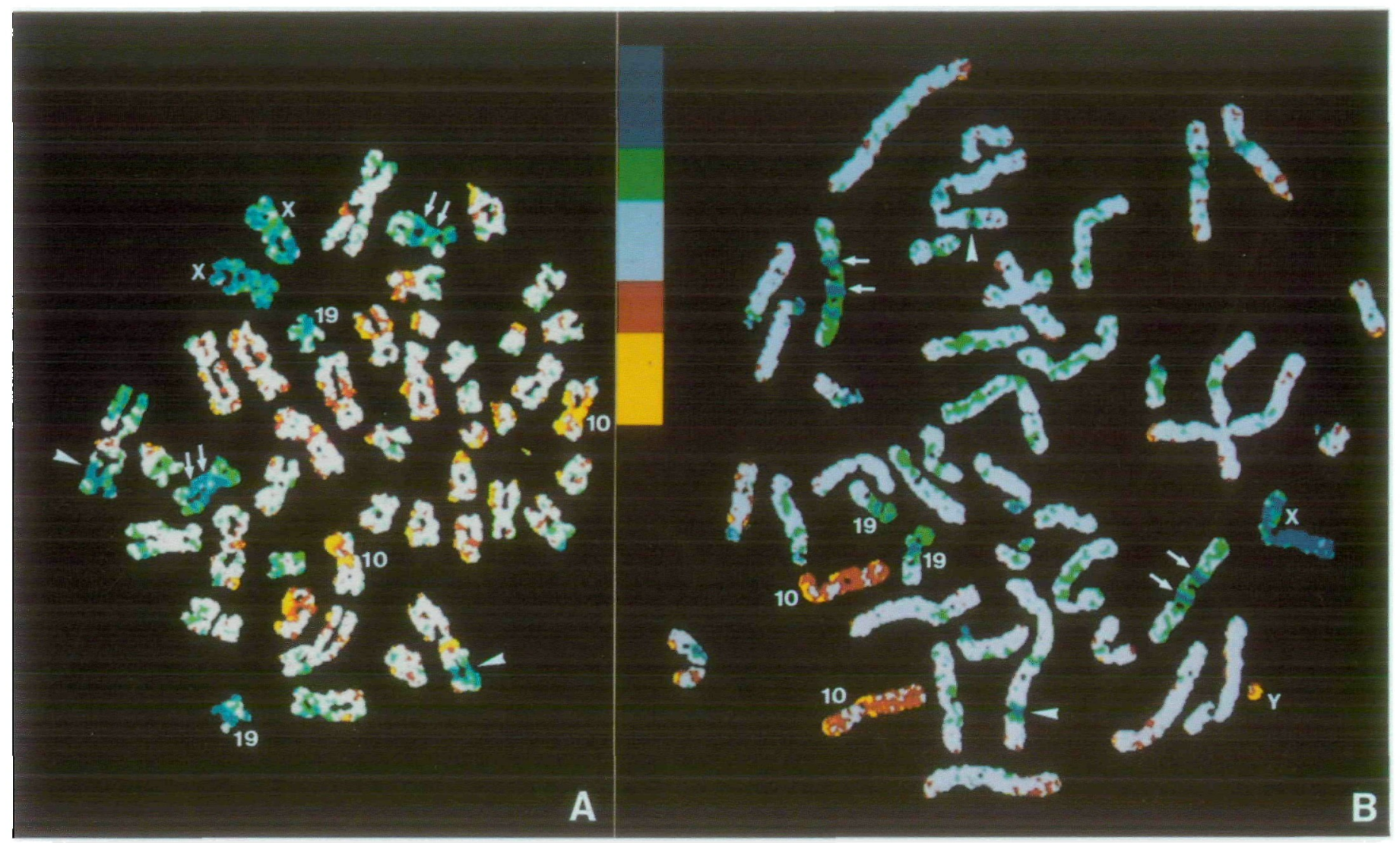

Figure 6. (A) FITC to TRITC ratio image of a normal female metaphase spread after CGH with DOP-PCR amplified DNA extracted from archival material of a glioblastoma of a female patient; (B) FITC to TRITC ratio image of a normal male metaphase spread after CGH with DNA extracted from fresh tissue of the same tumor. In both experiments the tumor DNA was detected with FITC, while normal male reference DNA was detected with TRITC. The look up table for displaying the ratio values is presented in the left upper comer: blue: range of ratio values $>2$ suggesting a copy number in the tumor more than twice the copy number present in the reference genome; green: range suggesting a trisomy; white: range suggesting a disomy; red: range suggesting a monosomy; yellow: range of ratios < 0.5 suggesting a strong underrepresentation or the complete absence of chromosome material. Accordingly in both metaphase spreads the color of the $\mathrm{X}$ chromosomes (expected ratio 2:1), of chromosomes 7, and of chromosomes 19 suggest a higher copy number in the glioma genome, while the color of chromosomes 10 suggests an underrepresentation. Note the yellow color of the $\mathrm{Y}$ chromosome in (B) reflecting the absence of this chromosome in the tumor genome. The blue region on chromosomes 1 (arrowhead) and two blue regions on chromosome 7 (arrows) are consistently seen in these and other metaphase spreads and indicative for the localization of DNA sequences with a highly increased copy mumber in the tumor genome. A detailed comparison of the colors seen along homologous chromosomes in the two metaphase spreads demonstrates the variability of the fluorescence ratio values obtained for individual chromosomes. Accordingly, in tumors with complex karyotypic changes it is rarely the case that all genetic imbalances can be seen in the ratio image of a single normal metaphase spread subjected to CGH. This variability stresses the importance of a statistical analysis of a number of metaphase spreads for an unequivocal interpretation (compare Fig. 7A,B).

alone underlines the importance of this technique, since each amplification site probably harbors genes, which are important for the tumor initiation or progression. The identification of overlap regions for chromosomes showing partial gains and losses by $\mathrm{CGH}$ of a series of tumors will pinpoint other regions of interest. As the development for universal PCR protocols will progress it is likely that $\mathrm{CGH}$ analyses will become possible even on a single cell basis. This might be achieved with a recently introduced modification consisting of a DNA pretreatment with topoisomerase I which increased the efficiency of DOP-PCR dramatically (23).

In the glioblastoma case described above we found abnormalities which were not detected with standard G-banding analyses or molecular genetic studies. We anticipate that comprehensive studies consisting of banding analyses whenever possible, molecular genetic studies, multicolor FISH with chromosome specific DNA probes (24-26), and CGH analyses will improve our understanding of causative mechanisms of solid tumors considerably. Each method provides unique data and the maximum of information will be obtained by a combination of all methods.

\section{MATERIALS AND METHODS}

\section{Metaphase spreads}

Metaphase spreads were prepared from phytohemagglutinin (PHA)-stimulated lymphocytes of healthy individuals $(46, \mathrm{XX}$ or $46, \mathrm{XY})$ using standard procetures of hypotonic treatment and methanol/acetic acid fixation $(3: 1, \mathrm{v} / \mathrm{v})$.

\section{Material}

To obtain DNA for the control experiments and as reference DNA for CGH experiments blood was drawn from healthy male and female donors. The cell line ACHN was established from a papillary renal cell carcinoma (7). All paraffin embedded tissues were evaluated by a pathologist. The glioma samples consisted microscopically solely of malignant cells without detectable 'contaminants' of normal tissue. 
A
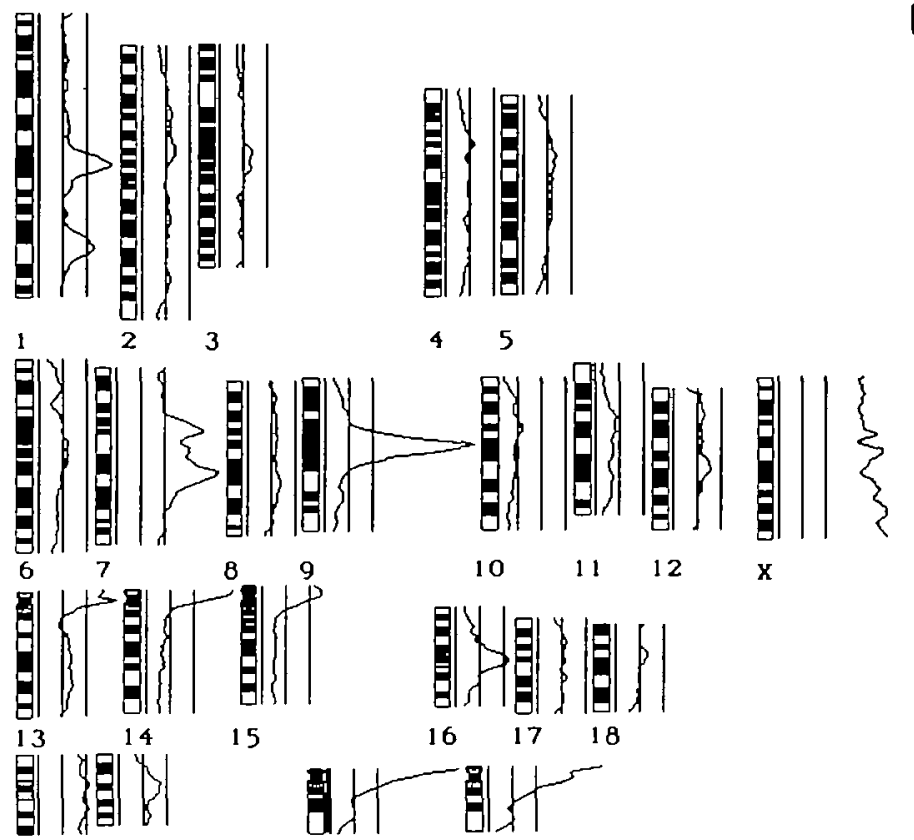

1920

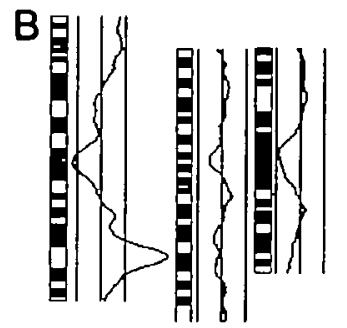

$\begin{array}{lll}1 & 2 & 3\end{array}$
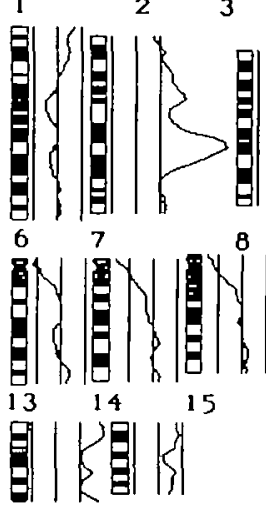

20

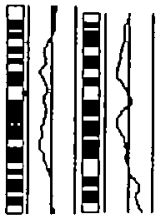

$4 \cdot 5$

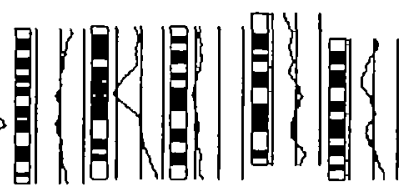

$\begin{array}{llll}9 & 10 & 11 & 12\end{array}$

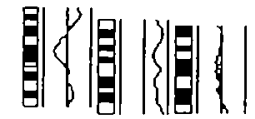

$\begin{array}{lll}16 & 17 & 18\end{array}$

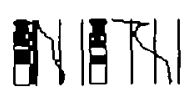

$21 \quad 22$

Figure 7. Average FITC (tumor DNA) to TRITC (reference DNA) ratio profiles. A) CGH experiment with glioma DNA extracted directly from fresh tumor (average profile obtained from 8 metaphases); B) CGH experiment with DNA extracted from paraffin embedded, formalin fixed tissue of the same glioma tumor as in A) after DOP-PCR (12 metaphases). Ratios along the individual chromosomes are shown on the right side of each chromosome. Left, middle and right vertical lanes represent the lower, middle and upper limits of the normal range. Due to the suppression with Cotl DNA fraction the heterochromatic blocks (in particular the centromeric regions of chromosomes 1, 9, 16, and the p-arms of all acrocentric chromosomes) yielded very low FITC and TRITC fluorescence intensities resulting in unreluable ratio values and are excluded from evaluation (detailed explanation see text). Note the ratio peaks on the q-arm of chromosome 1 and the p-and $q$-arms of chromosome 7, representung amplification sites. Higher copy numbers within the tumor genome for the chromosomes 7 and $X$ as well as the decreased copy number for chromosome 10 are readily visible in both experiments. The consistently elevated (borderline in A) and clearly above the normal range in B) ratio values for chromosome 19 demonstrate the existence of a chromosome 19 gain in a major subclone of this tumor.

\section{DNA extraction procedures and cell counting}

Genomic DNA was prepared from blood of healthy male and female donors and from the cell line ACHN following standard protocols (27).

DNA extraction from formalin fixed, paraffin embedded tissues required several modifications: Paraffin embedded tissues were incubated for several hours at $65^{\circ} \mathrm{C}$. Dewaxing was done with 3 changes of Xylol, 10 minutes each at room temperature, and 2 changes of Methanol, 5 minutes each at room temperature. Sections containing tumor material as diagnosed earlier by a pathologist were scratched from the slide and transferred to in an eppendorf tube. The average size of the scratched tumor material was about 2 to $3 \mathrm{~mm}^{3}$. The tissue was incubated overnight in $1 \mathrm{ml} 1 \mathrm{M}$ sodium thiocyanate at $37^{\circ} \mathrm{C}$.

For establishing the minimal numbers of formalin fixed nuclei for DOP-PCR, in some cases the nuclei were isolated after the sodium thiocyanate step according to previously published protocols (14): tissues were digested with Pepsin $(4 \mathrm{mg} / \mathrm{ml})$, adjusted to $\mathrm{pH} 2.0$ with $2 \mathrm{~N} \mathrm{HCL}$ at $37^{\circ} \mathrm{C}$. The cells were washed in distilled water and the cell number established by counting the cells of this cell suspension using a 'Neubauer-cell-count-chamber'.

The tissue samples or the cell suspensions after counting were then washed twice with DNA isolation buffer $(75 \mathrm{mM} \mathrm{NaCl}, 25 \mathrm{mM}$ EDTA, $0.5 \%$ Tween 20) and $40 \mu$ Proteinase $K(10 \mathrm{mg} / \mathrm{ml})$ added for overnight incubation at $55^{\circ} \mathrm{C}$. SDS was omitted since it reduces Taq Polymerase activity. Phenol/chloroform DNA extraction ( $2 \times$ Phenol; $2 \times$ Phenol/Chloroform; $1 \times$ Chloroform) followed by ethanol precipitation was done the next day.

\section{Estimation of DNA concentration}

In order to estimate the extracted DNA concentrations, $1 \mu$ l of extracted DNA was placed on an ethidium bromide plate.

\section{DOP-PCR}

DOP-PCR was performed as described $(4,5)$ on a Thermocycler 60 (Bio-med) in a $50 \mu$ reaction volume $(2 \mathrm{mM} \mathrm{MgCl}, 50 \mathrm{mM} \mathrm{KCl}, 10 \mathrm{mM}$ Tris HCl, $\mathrm{pH}$ $8.4,10 \mu \mathrm{g} / \mathrm{ml}$ gelatine, $200 \mu \mathrm{M}$ of each dNTP, $1.7 \mu \mathrm{M}$ primer 6-MW [5'-CCG ACT CGA GNN NNN NAT GTG $G-3^{\prime}$, with $N=A, C, G$, or $T$ in approximately equal proportions] and $2.5 \mathrm{U}$ Taq polymerase [Perkin-Elmer Cetus]) with $10 \mathrm{~min}$ at $93^{\circ} \mathrm{C}$, followed by five cycles of $1 \mathrm{~min}$ at $94^{\circ} \mathrm{C}, 1.5 \mathrm{~min}$ at $30^{\circ} \mathrm{C}, 3 \mathrm{~min}$ transition $30-72^{\circ} \mathrm{C}$, and $3 \mathrm{~min}$ extension at $72^{\circ} \mathrm{C}$, followed by 35 cycles of 1 min at $94^{\circ} \mathrm{C}, 1 \mathrm{~min}$ at $62^{\circ} \mathrm{C}$, and $3 \mathrm{~min}$ at $72^{\circ} \mathrm{C}$, with an addition of $1 \mathrm{sec} / \mathrm{cycle}$ to the extension step and a final extension of $10 \mathrm{~min}$.

\section{DNA labeling}

The genomic DNA and the DOP-PCR amplification products were labelod with digoxigenin-1 1-dUTP or biotin-1 1-dUTP using standard nick-transhation procedures (28).

\section{CGH}

CGH was done as described previously (3) with minor modifications. Briefly, $100-200 \mathrm{ng}$ of biotinylated tumor DNA or DOP-PCR amplification product was mixed with the same amount of normal digoxigenin labeled reference DNA and hybridized in the presence of $50 \mu \mathrm{g}$ Cot1-DNA and $50 \mu \mathrm{g}$ sonicated salmon DNA. Hybridization was allowed for four to five days. Probe detection was carried out as described (3).

\section{Image acquisition}

Image acquisition and image processing were performed as detailed in (3). Briefly, for image acquisition an epifluorescence microscope (Zeiss Axiophot) equipped with a cooled CCD-camera (Photometrics, Tucson, AZ) with the Kodak 1400 chip $(1317 \times 1035$ pixels) interfaced to a Quadra 900 was used. For image recording, a selected area of $512 \times 512$ pixels was adjusted to the optical center of the microscope field and gray level images were taken separately for each fluorochrome using the appropriate filter sets.

\section{Image processing and evaluation}

To define an empirical threshold for the unequivocal identification of gains or losses, as used in Fig. 2 and 4, control CGH experiments with mixtures of biotinand digoxigenin-labeled control DNA $(46, X Y)$ were carried out. The mean of the fluorescence ratio values and the limits of the $95 \%$ confidence interval (mean 
$+1-1.96$ times the standard deviation of the mean) were calculated (3). Chromosomes with fluorescence ratios outside the confidence interval were considered to be over- or underrepresented, respectively.

Digital images were processed with programs developed in our laboratory (du Manoir et al., manuscript in preparation) using the software package TCL Image (Multihouse, Amsterdam, The Netherlands). Image shifts were corrected using the gravity center of a designated chromosome in the DAPI, FITC, and TRITC image, respectively. To obtain FITC to TRITC pixel by pixel ratio images of one metaphase spread (Fig. 3B and Fig. 6A,B) a FTTC image was divided (pixel by pixel) by the TRITC image. After normalization procedures a three color (Fig. 3B) or five color (Fig. 6A,B) look-up table was used for the visualization of gray levels below, under or within the threshold of the normal range.

The procedure for the calculation of FTTC and TRITC mean ratio profiles includes the following steps: Firstly, the determination of the medial axis of each chromosome within the DAPI image as described by Kallioniemi et al. (2). Secondly, the calculation of the FITC and TRITC profiles using a resampling perpendicular to the medial axis and profile ratio calculations. Thirdly, for each chromosome type an averaging of individual chromosome ratio profiles from different metaphases. The detailed procedure will be described elsewhere (du Manoir et al., manuscript in preparation).

\section{ACKNOWLEDGEMENTS}

We are grateful to Dr G.Kovecs (University of Zurich, Switzerland) for providing the renal carcinoma cell line ACHN, Dr S.Stötrel (University of Mainz, Germany) for cell suspensions of formelin fixed renal tumors, Dr G.Thiel and Dr P.Nümberg (Humboldt University, Berlin, Germany) for DNA and tissue samples from gliomas.

\section{ABBREVIATIONS}

$\begin{array}{ll}\text { CCD: } & \text { charge coupled device } \\ \text { CGH: } & \text { comparative genomic hybridization } \\ \text { DAPI: } & 4^{\prime}, 6^{\prime} \text {-diamidino-2-phenylindole } \\ \text { DMs: } & \text { double minute chromosomes } \\ \text { DOP-PCR: } & \text { degenerate oligonucleotide primed-PCR } \\ \text { FLH: } & \text { fluorescence in situ hybridization } \\ \text { FTTC: } & \text { fluorescein isothiocyanate } \\ \text { HSRs: } & \text { homogeneously staining regions } \\ \text { PBS: } & \text { phosphate buffered saline } \\ \text { SDS: } & \text { sodium dodecyl sulfate } \\ \text { TRITC: } & \text { tetramethylrhodamine isothiocyanate }\end{array}$

\section{REFERENCES}

1. Mitelman, F., Kaneko, Y., and Trent, J. (1991) Cytogenet Cell Genet 58, $1053-1079$.

2. Kallioniemi, A., Kallioniemi, O.-P., Sudar, D., Rutoviz, D., Gray, J.W., Waldman, F., and Pinkel, D. (1992) Science 258, 818-821.

3. du Manoir, S., Speicher, M.R., Joos, S., Schröck, E., Popp, S., Döhner, H., Kovacs, G., Robert-Nicoud, M., Lichter, P., and Cremer, T. (1993) Hum Genet 90, 590-610.

4. Telenius, H., Pelmear, A.H., Tunnacliffe, A., Carter, N.P., Behmel, A., Furgoson-Smith, M.A., Nordenskjołłd, M., Pfragner, R., and Ponder, B.A.J. (1992) Genes, Chromosomes \& Cancer 4, 257-263.

5. Telenius, H., Carter, N.P., Bebb, C.E., Nordenskjöld, M., Ponder, B.A.J., and Tunnacliffe, A. (1992) Genomics 13, 718-725.

6. Joos, S., Scherthan, H., Speicher, M.R., Schlegel, J., Cremer, T., and Lichter, P. (1993) Hum Genet 90, 584-589.

7. Kovacs, G., Fuzesi, L., Emanued, A., Kung, H. (1991) Genes, Chromosomes \& Cancer 3, 239-255.

8. Higuchi, R. (1989) In Erlich, H.A. (ed.): PCR Technology, Principles and applications for DNA amplification, Stockton Press, New York, pp. $31-38$.

9. Goelz, S.E., Hamilton, S.R., Vogelstein, B. (1985) Biochem Biophys Res Commun 130, 118-126.

10. Shibata, D.K., Martin, W.J., Amheim, N. (1988) Cancer Res 48, $4564-4566$.

11. Shibata, D.K., Amheim, N., Martin, J.W. (1988) J Exp Med 167, 225-230.

12. Ben-Ezra, J., Johnson, D.A., Rossi, J., Cook, N., and Wu, A. (1991) J Histochem Cytochem 39, 351-354.

13. Stein, A., Raoult, D. (1992) Nucleic Acids Research 20, 5237-5238.

14. Hedley, D.W., Friedlander, M.L., Taylor, I.W., Rugg, C.A., and Musgrove, E.A. (1983) J Histochem Cytochem 31, 1333-1335.

15. Zülch, K.J. International histological classification of tumours No.21:
Histological typing of tumours of central nervous system. WHO, Geneva. 16. Thiel, G., Lozanova, T., Vogel, S., Kmzed, D., Jänisch, W., and, Wrtkowski, R. (1992) Cancer Genet Cytogent 58, 109-120.

17. Nürnberg, P., Zischler, H., Fuhmann, E., Thiel, G., Lozanova, T., Kinzel, D., Nisch, G., Witkowski, R., and, Epplen, J.T. (1991) Genes Chrom Cancer 3, 79-88.

18. Zhang, L., Cui, X., Schmitt, K., Hubert, R., Navidi, W., and Amheim, N. (1992) Proc Natl Acad Sci USA 89, 5847-5851.

19. Milan, D., Yerle, M., Schmitz, A., Chaput, B., Vaiman, M., Frelat, G., and Gellin, J. (1993) Cytogenet Cell Genet 62, 139-141.

20. Morton, N.E. (1991) Proc Natl Acad Sci USA 88, 7474-7476.

21. Hopman, A.H.N., van Hooren, E., van de Kaa, C.A., Vooijs, G.P., Ramaekers, F.C.S. (1991) Modern Pathology 4, 503-513.

22. Tannock, I.F. (1989) In DeVita, V.T., Hellman, S., Rosenberg, S.A. (eds.): Cancer, Principles \& Practice of Oncology, 3rd Edition, J.B. Lippincott Company, Philadelphia, pp. 3-13.

23. Guan, X.-Y., Trent, J.M., and Meltzer, P.S. (1993) Hum Molec Genet 2, $1117-1121$.

24. Ried, T., Baldini, A., Rand, T.C., and Ward, D.C. (1992) Proc Natl Acad Sci USA 89, 1388-1392.

25. Lengauer, L., Speicher, M.R., Popp, S., Jauch, A., Taniwaki, M., Nagaraja, R., Riethman, H.C., Donis-Keller, H., D'Urso, M., Schlessinger, D., and Cremer, T. (1993) Hum Molec Genct 5, 505-512.

26. Popp, S., Jauch, A., Schindler, D., Speicher, M.R., Lengauer, C., DonisKeller, H., Riethman, H.C., and Cremer, T. (1993) Hum Genet, in press.

27. Maniatis, T., Fritsch, E.F., and Sambrook, J. (1982) Molecular Cloning: A Laboratory Manual Cold Spring Harbor.

28. Lichter, P., and Cremer, T. (1992) In Rooney, D.E., and Czepulkowski (eds.): Human Cytogenetics (Vol I): A practical approach, 2nd Edition, IRL Press, Oxford, pp. 157-192. 